Goldschmidt 2021 Abstract

https://doi.org/10.7185/gold2021.7562 https://nsf2026imgallery.skild.com/entries/bridging-the-atom-to-globalscale-gap.

\section{Assessing ecohydrological resilience across scales: opportunities and challenges for Critical Zone research}

JULIA PERDRIAL ${ }^{1}$, CAITLIN BRISTOL ${ }^{1}$, MANYA RUCKHAUS $^{1}$, ERIN SEYBOLD ${ }^{2}$, BRYN STEWART ${ }^{3}$, BEN W ABBOTT ${ }^{4}$, DUSTIN W KINCAID ${ }^{1}$, KRISTEN

UNDERWOOD $^{1}$, SCOTT D HAMSHAW ${ }^{1}$, JAMES B SHANLEY $^{5}$, LI LI $^{3}$, DONNA RIZZO ${ }^{1}$, RAYMOND LEE ${ }^{4}$, GABRIEL LEWIS ${ }^{6}$ AND BYUNG SUK LEE ${ }^{1}$

${ }^{1}$ University of Vermont

${ }^{2}$ University of Kansas

${ }^{3}$ Penn State University

${ }^{4} \mathrm{BYU}$

${ }^{5}$ USGS

${ }^{6}$ University of Nevada Reno

Presenting Author: julia.perdrial@uvm.edu

Disturbances in the Critical Zone (CZ), such as land-cover transformation, amplification of biogeochemical flows, and climate changes are triggering transitions that are unprecedented in spatial and temporal scales and, thus, need careful study across scales. However, attributing a $\mathrm{CZ}$ response at the catchment scale to its specific driver is challenging because the scale of disturbance often transcends the spatial and temporal bounds of individual sites that have highly heterogeneous spatial characteristics. Research shows that direct scaling of site-specific observations to a larger and/or longer scale trend (and vice versa) might not be feasible and that scaling mismatches might be the norm rather than the exception (Beven, 2001; Levin, 1992; NSF, 2018). An alternative to direct upscaling and downscaling in order to understand larger/longer-scale patterns and site-specific processes is an iterative framework. As part of the newly funded CZ collaborative network cluster focused on using Big Data approaches to assess ecohydrological resilience across scales, we are developing an iterative "pattern-to-process" and "process-topattern" approach to investigate how the $\mathrm{CZ}$ structure controls ecohydrological dynamics and responds to overlapping disturbances in the context of multi-dimensional resilience - that is, how the $\mathrm{CZ}$ structure resists disturbances and/or recovers from them by regulating the linkages among multiple dimensions of habitats and services. Using both regional scale data and sitespecific experiments, we will show examples of how ecohydrological dynamics influenced by the terrestrial-aquatic interfaces respond to disturbances in the northeastern US. We will integrate these examples into our conceptual framework of multi-dimensional resilience and discuss challenges and opportunities with scaling and the combination of data-driven approaches in this context.

Beven, K.J. (2000). Uniqueness of place and process representations in hydrological modelling. Hydrology and Earth System Sciences Discussions 4, 203-213.Levin, S.A. (1992). The Problem of Pattern and Scale in Ecology: The Robert H. MacArthur Award Lecture. Ecology 73, 1943-1967. NSF (2018). Bridging the Atom-to-Global Scale Gap [Online]. 